\title{
Ethanol extract from Epimedium brevicornum attenuates left ventricular dysfunction and cardiac remodeling through down-regulating matrix metalloproteinase-2 and -9 activity and myocardial apoptosis in rats with congestive heart failure
}

\author{
YAO-HONG SONG, BAO-SHI LI, XIANG-MIN CHEN and HUI CAI \\ Department of Integrated Traditional Chinese and Western Medicine, Nanjing General Hospital of \\ Nanjing Military Command, 305 Zhongshandong Road, Nanjing 210002, P.R. China
}

Received August 21, 2007; Accepted October 2, 2007

\begin{abstract}
Epimedium, a traditional Chinese herb, has been used for the remedy of coronary heart disease, impotence and osteoporosis in traditional oriental medicine. However, despite extensive pharmacological studies, the molecular mechanism of the anti-heart failure effect of epimedium is little known. In the present study, we investigated the pharmacological action mechanism of ethanol extract of epimedium (EPI-ext) on isoproterenol-induced congestive heart failure (CHF) in rats. Isoproterenol administration resulted in severe heart failure, as shown by the increased levels of left ventricular (LV) weight index and heart rate, as well as LV end diastolic pressure, and by the decreased levels of LV systolic pressure, maximal rate of LV pressure rise, and maximal rate of LV pressure decline. EPI-ext dose-dependently reversed the changes of these cardiac morphometric and hemodynamic parameters. In addition, EPI-ext significantly inhibited the serum levels of tumor necrosis factor $\alpha$, norepinephrine, angiotensin II and brain natriuretic peptide in rats with $\mathrm{CHF}$ and improved the histological changes including cadiocyte hypertrophy, cadiocyte degeneration, inflammatory infiltration, and cardiac desmoplasia. Furthermore, the expression and activities of matrix metalloproteinase-2 and -9 , which regulate collagen production, were also blocked by EPI-ext. Moreover, myocardial apoptosis was remarkably attenuated by EPI-ext through the regulating $\mathrm{Bcl}-2 / \mathrm{Bax}$ axle. In conclusion, EPI-ext ameliorates LV dysfunction and cardiac remodeling through down-regulating matrix
\end{abstract}

Correspondence to: Dr Hui Cai, Department of Integrated Traditional Chinese and Western Medicine, Nanjing General Hospital of Nanjing Military Command, 305 Zhongshandong Road, Nanjing 210002, P.R. China

E-mail: phdcaihui@163.com

Key words: epimedium, congestive heart failure, cardiac remodeling, matrix metalloproteinase, myocardial apoptosis metalloproteinase-2 and -9 activity and myocardial apoptosis in rats with $\mathrm{CHF}$.

\section{Introduction}

Congestive heart failure $(\mathrm{CHF})$ is a severe cardiovascular disease with increasing incidence and prevalence. Despite recent advances in CHF therapy, mortality remains high (1). Therefore, new therapeutic remedies or approaches are needed to decrease morbidity and mortality in heart failure patients. CHF is invariably associated with cardiac hypertrophy, and the changes in the cardiac remodeling (shape and size of cadiocyte) are often considered to explain cardiac dysfunction in CHF. Noteworthy, left ventricular (LV) remodeling is a dynamic response of the heart to injury and a critical component in the development of CHF. There is increasing evidence that inhibition of cardiac remodeling may be a promising novel therapeutic approach for the treatment of CHF (2-4). Several lines of evidence both from various experimental models of $\mathrm{CHF}$ and from patients with different types of CHF have indicated that the elevated matrix metalloproteinase (MMP) activity and myocardial apoptosis are responsible for cardiac remodeling (5-7). Some previous studies have indicated that both the angiotensinconverting enzyme inhibitors and $\beta$-blocking agents improve cardiac function in failing hearts through attenuating changes in cardiac remodeling such as sarcolemma, sarcoplasmic reticulum, and myofibril enzyme activities $(4,8,9)$. It is suggested that cardiac remodeling is an excellent target for the development of improved drug therapy for CHF. Thus, inhibition of cardiac remodeling may be a promising novel therapeutic approach for the treatment of CHF.

On the other hand, epimedium, a traditional Chinese herb, is widely used for treating various diseases including coronary heart disease, impotence and osteoporosis (10-12). Epimedium is one representative of traditional Chinese medicine derived from Shen Nong Ben Cao Jing, a pharmaceutical classic in China. Extract of epimedium has been shown to have a protective role in experimental myocardial infarction in rats (13), and it also enhances the proliferation 
of splenocytes and thymocytes (14). In addition, the major active substances of epimedium include icariin, epimedoside, icariside, breviflavone and ikarisoside, most of which possess anti-hepatotoxic, immunomodulatory, anti-tumor, antidepressant and anti-oxidant activities (15-20). However, the molecular mechanism of the anti-heart failure effect of epimedium is poorly understood. In the present study, we investigated the effect of ethanol extract of epimedium on $\mathrm{CHF}$ induced by isoproterenol in rats. The mechanisms were then elucidated in terms of MMP production and myocardial apoptosis.

\section{Materials and methods}

Animal model and echocardiography measurements. Adult, healthy, male Sprague-Dawley rats (230-280 g) were chosen for the induction of experimental heart failure using a modified isoproterenol administration method (21). Briefly, all rats received two subcutaneous injections (separated by a 24-h interval) of $170 \mathrm{mg}$ isoproterenol per $\mathrm{kg}$ of body weight. Echocardiography was performed on animals 4 weeks after completion of the injection protocol to evaluate the degree of The heart failure in the rats. Rats were anesthetized with pento-barbital sodium (35 $\mathrm{mg} / \mathrm{kg}$ i.p.), then the chest was shaved and the rat was placed in the supine position. Transthoracic echocardiography was performed with a Sonos 5500 and a 7.5-MHz transducer (Hewlett-Packard). The heart was imaged in the 2-dimensional mode in short-axis view of the LV at the level of the papillary muscle. All rats with an ejection fraction $>45 \%$ were excluded after the echocardiography examination (22). The remaining rats, with an ejection fraction $<45 \%$, were randomly divided into five groups: control group $(\mathrm{n}=15)$, metoprolol $8 \mathrm{mg} / \mathrm{kg} /$ day group $(\mathrm{n}=12)$, EPI-ext $50 \mathrm{mg} / \mathrm{kg} /$ day group ( $\mathrm{n}=11)$, EPI-ext $100 \mathrm{mg} / \mathrm{kg} /$ day group $(\mathrm{n}=10)$, EPI-ext $200 \mathrm{mg} / \mathrm{kg} /$ day group $(\mathrm{n}=12)$. The drugs were given i.g. at the specified doses for 8 weeks. Then, the animals were anesthetized in order to measure hemodynamic parameters including LV systolic pressure (LVSP), LV end diastolic pressure (LVEDP), maximal rate of $\mathrm{LV}$ pressure rise $\left(\mathrm{dp} / \mathrm{dt}_{\max }\right)$ and maximal rate of $\mathrm{LV}$ pressure decline $\left(\mathrm{dp} / \mathrm{dt}_{\min }\right)$. The animals were then sacrificed using intravenous pentobarbital sodium $(100 \mathrm{mg} / \mathrm{kg})$. The hearts were removed, weighed, and rinsed in ice-cold normal saline. The ventricles were separated from the septum and weighed. Transmural samples from LV were processed immediately or stored in liquid nitrogen for later analysis. Animal welfare and experimental procedures were carried out strictly in accordance with the Guide for the Care and Use of Laboratory Animals (The Ministry of Science and Technology of P.R. China, 2006) and the related ethical regulations of our hospital.

Hemodynamic measurements. After anesthetic induction, the left carotid artery was exposed through blunt dissection and cannulated with a saline-filled catheter. The catheter was attached to a pressure transducer and introduced into the LV in order to measure LVSP, LVEDP, $\mathrm{dp} / \mathrm{dt}_{\max }$ and $\mathrm{dp} / \mathrm{dt}_{\min }$. All hemodynamic data were recorded on a BL-410 biological functional experimental system (Taimeng Science and Technology Co. Ltd., Chengdu, P.R. China) and analysed by BL-NewCentury software.
Drugs and reagents. The crude drug was purchased from Nanjing Medical Material Co. (Nanjing, P.R. China) and identified as Epimedium brevicornum Maxim. (Yin-YangHuo) by Dr Yue Song (China Pharmaceutical University, Nanjing, P.R. China). The ethanol extract of epimedium (EPI-ext) used in this study was extracted by a common method. Briefly, the material (100 g) was extracted twice with 5 -fold volumes of ethanol $(500 \mathrm{ml})$ at $70^{\circ} \mathrm{C}$ for $1 \mathrm{~h}$ each time. The supernatants from each extraction were mixed and centrifuged at $1500 \mathrm{~g}$, then the precipitation was discarded and the supernatant was lyophilized to obtain a powder (yield $23.1 \%$, w/w). The extract used was from the same stock solution in each experiment, thus minimizing the possible variations in the concentration of the active components that occur between extract preparations. The main component in EPI-ext was determined by HPLC as $16.7 \%$ (w/w) icariin. The powder was dissolved in water for in vivo assay by gavage oval administration to the rats. The following materials were used: isoproterenol (Sigma); metoprolol tartarte (AstraZeneca); a kit for determining serum tumor necrosis factor $\alpha$ (TNF- $\alpha$, General Hospital of the Liberation Army, Radioimmunity Center, Nanjing, P.R. China); angiotensin II (Ang II, Beijing North Biotech Co. Ltd., Beijing, P.R. China); brain natriuretic peptide (enzyme immunoassay goat anti-rat BNP, Adlitteram Diagnostic Laboratories, Inc. USA); ELISA kit for rat norepinephrine (NE, RapidBio Lab., Calabasas, CA, USA); 96-well culture plates (Nunclon); RPMI-1640 (Gibco BRL); new bovine serum (NBS, Hangzhou Sijiqing Co. Ltd., Hangzhou, P.R. China); mouse anti-Bcl-2 monoclonal antibody, mouse anti-Bax monoclonal antibody and anti- $\alpha$-tubulin (Santa Cruz Biotechnology), and cleaved caspase-3 and cleaved caspase-9 antibodies (Cell Signaling Technology).

Histologic analysis. Formalin-fixed, paraffin-embedded ear tissue was sectioned at $5 \mathrm{~mm}$ in thickness, and the sections were stained with hematoxylin and eosin $(\mathrm{H} \& \mathrm{E})$ and masson, respectively. Histopathologic scoring was performed using a range from 0 (no change) to 4 (most severe) to evaluate congestion, edema, and inflammatory cell infiltration by a pathologist who had no prior knowledge of the induction of heart failure or other experimental data.

Reverse transcriptase-polymerase chain reaction ( $R T-P C R)$ and real-time PCR. Total RNA was extracted from frozen left ventricular tissue using Trizol reagent (Invitrogen) as described by the manufacturer. Single-stranded cDNA was synthesized from $2 \mu \mathrm{g}$ of total RNA by reverse transcription using $0.5 \mu \mathrm{g}$ primer of oligo $(\mathrm{dT})_{18}$. Then the amplification was performed using the following primers (Invitrogen, Shanghai, P.R. China): GAPDH (GenBank Access no. NM_017008) 5'-TAT CGGACGCCTGGTTAC and 3'-CGTTCAAGTTGCCGT GTC, MMP-2 (GenBank Access no. NM_031054) 5'-GGA GGCACGATTGGTCTG and 3'-TCTGGTACGCCTTTG GTT, MMP-9 (GenBank Access no. NM_031055) 5'-CTG CGTATTTCCATTCATC and 3'-GAGATTTGGACTGGG TTCC. The PCR cycle conditions were: $94^{\circ} \mathrm{C}$ for $30 \mathrm{sec}$, $58^{\circ} \mathrm{C}$ for $30 \mathrm{sec}$ and $72^{\circ} \mathrm{C}$ for $30 \mathrm{sec}$ for 28 cycles. After the amplification, PCR products were separated by electrophoresis on $1.5 \%$ agarose gels and visualized by ethidium 
bromide dying. RNA without reverse transcription did not yield any amplification; therefore, no genomic DNA contamination occurred. For quantitative real-time PCR analysis, message levels were quantified using the ABI PRISM 7000 Sequence Detection System (Applied Biosystems Inc.). Amplification was carried out in a total volume of $20 \mu \mathrm{l}$ for 40 cycles with the same PCR condition mentioned above and the product was detected using SYBRGreen I dye (Molecular Probes Inc., OR). Samples were run in triplicate, and their relative expression was determined by normalizing expression of each target to GAPDH, and then comparing this normalized value to the normalized expression in a reference sample to calculate a fold-change value.

Gelatin zymography assay. Analysis by zymography on gelatin gel allows detection of the enzymatic activity of the secreted collagenases MMP-2 and -9 (23). Briefly, protein was extracted from frozen LV tissue and aliquots containing $10 \mu \mathrm{g}$ of protein were mixed with $10 \mu 1$ sample buffer [62.5 mM Tris- $\mathrm{HCl}$ containing $10 \%$ glycerol, $0.00125 \%$ bromophenol blue and $12 \%$ sodium dodecyl sulfate (SDS)] without a reducing agent, and they were subjected to SDS-PAGE in 5\% polyacrylamide gels that were co-polymerized with $2 \mathrm{mg} / \mathrm{ml}$ of gelatin at $4^{\circ} \mathrm{C}$ for $1 \mathrm{~h}$. After electrophoresis, the gels were washed twice in the rinsing buffer $(50 \mathrm{mM}$ Tris- $\mathrm{HCl}$ containing $2.5 \%$ Triton X-100, $5 \mathrm{mM} \mathrm{CaCl}_{2}, 1 \mu \mathrm{M} \mathrm{ZnCl}_{2}, 0.05 \% \mathrm{NaN}_{3}$ ) for $1 \mathrm{~h}$ at room temperature to remove SDS. Then, they were incubated for $36 \mathrm{~h}$ at $37^{\circ} \mathrm{C}$ in the incubation buffer $(50 \mathrm{mM}$ Tris- $\mathrm{HCl}$ containing $5 \mathrm{mM} \mathrm{CaCl}_{2}, 1 \mu \mathrm{M} \mathrm{ZnCl}_{2}, 0.05 \% \mathrm{NaN}_{3}$ ). The gels were stained with $0.1 \%$ Coomassie brilliant blue R250 for $30 \mathrm{~min}$, and destained for $8 \mathrm{~h}$ in a solution of $10 \%$ acetic acid and $10 \%$ isopropanol. The proteolytic activity was evidenced as clear bands (zones of gelatin degradation) against the blue background of stained gelatin.

DNA fragmentation analysis. The electrophoresis of DNA fragmentation was performed as previously described (24).

Western blot analysis. Protein was extracted from frozen left ventricular tissue. Protein concentration was determined by using a bicinchoninic acid protein assay reagent (Pierce; Rockford, IL) and bovine serum albumin as a standard. Aliquots containing $30 \mu \mathrm{g}$ of protein were loaded on $10 \%$ SDS-PAGE. Proteins were transferred to a polyvinylidene difluoride membrane. The membrane was then incubated in blocking solution (5\% dry milk in PBS/0.05\% Tween-20) for $1 \mathrm{~h}$ at room temperature and subsequently exposed to antibodies overnight at $4{ }^{\circ} \mathrm{C}$. The next day the membrane was washed with $0.05 \%$ Tween-20 in PBS and incubated with peroxidase-conjugated goat anti-mouse or goat anti-rabbit $\mathrm{IgG}$ for $2 \mathrm{~h}$ at room temperature. The transferred proteins were visualized with X-ray film.

HPLC analysis of the content of icariin in the ethanol extract of epimedium. All the content tests were applied on the Waters 600 pump, with a 2487 ultraviolet-vis detector, an online degasser, and a 5- $\mu 1$ injection loop. EPI-ext was applied to a C18 column (Kromasil, $4.6 \times 250 \mathrm{~mm}, 5 \mu \mathrm{m}$ ) and eluted with $\mathrm{CH}_{3} \mathrm{OH} / \mathrm{H}_{2} \mathrm{O}(45 / 55, \mathrm{v} / \mathrm{v})$. The effluents were

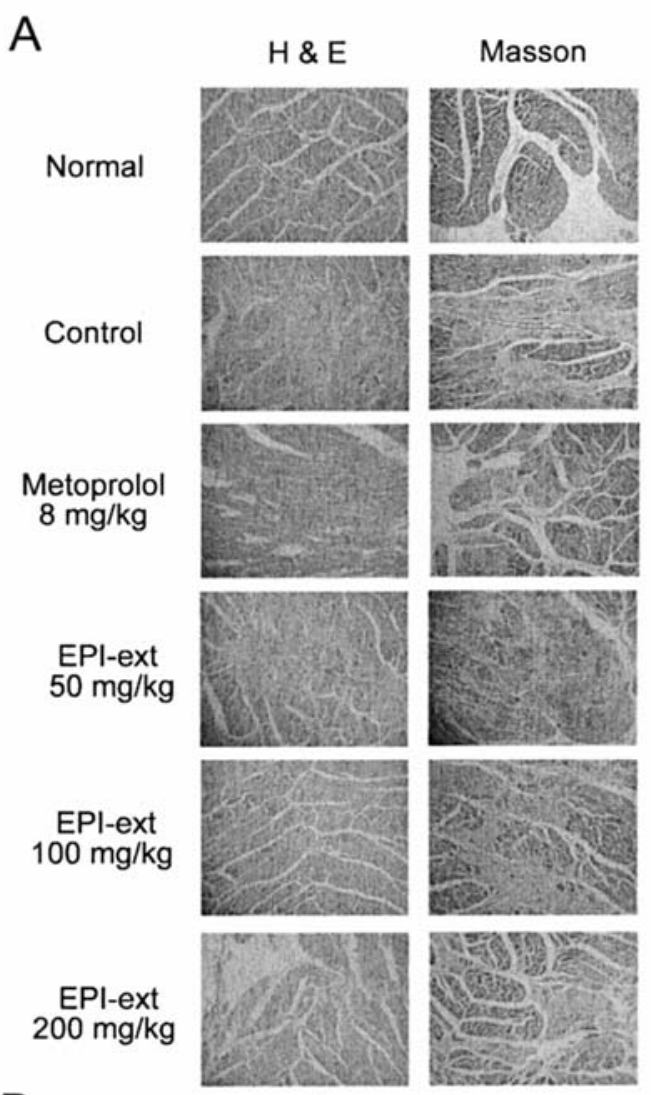

B

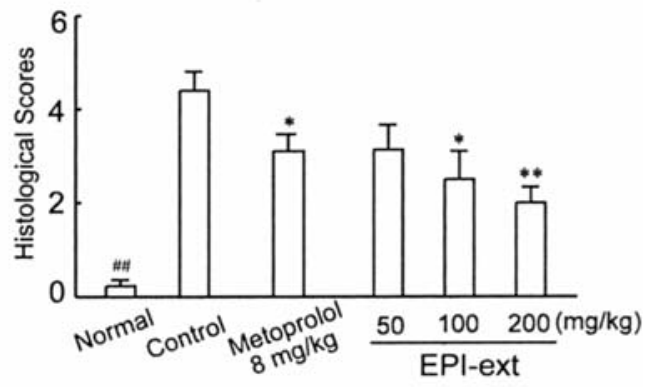

Figure 1. Effect of EPI-ext on histopathological changes of the LV remodeling in rats with CHF caused by isoproterenol. (A) Hematoxylin and eosin (H\&E) and masson staining (original magnification $\mathrm{x} 100$ ). Normal, normal rats; control, model rats treated with normal saline after isoproterenol injection; metoprolol, model rats treated with metoprolol after isoproterenol injection; EPI-ext, model rats treated with EPI-ext after isoproterenol injection. (B) LV histologic scoring. Each column indicates the mean \pm SEM of $6-9$ rats. ${ }^{\# \#} \mathrm{P}<0.01$ vs control (Student's t-test); ${ }^{*} \mathrm{P}<0.05$, ${ }^{* *} \mathrm{P}<0.01$ vs control (Dunnett's test).

detected under $275 \mathrm{~nm}$. Column temperature was set at $25^{\circ} \mathrm{C}$ and the flow rate was $1 \mathrm{ml} / \mathrm{min}$. For peak assignment, the standard compound (icariin) was applied to HPLC and eluted under the same chromatographic conditions as those used in EPI-ext. The peaks representing constituents of EPI-ext were identified by comparing their retention time with the standard compounds. The peak areas and the relative contents were calculated using Empower ${ }^{\mathrm{TM}}$ workstation.

Statistical analysis. Results are presented as means \pm SEM. Data were statistically evaluated by the Student's t-test when only two value sets were compared, and one-way ANOVA 
Table I. Cardiac morphometric and hemodynamic parameters in rats 12 weeks after isoproterenol injection treated either with normal saline, metoprolol or various doses of EPI-ext.

\begin{tabular}{|c|c|c|c|c|c|c|}
\hline \multirow[t]{2}{*}{ Parameter } & \multirow[t]{2}{*}{ Normal (n=8) } & \multicolumn{5}{|c|}{ Isoproterenol injection } \\
\hline & & $\begin{array}{l}\text { Control } \\
(n=10)\end{array}$ & $\begin{array}{l}\text { Metoprolol } \\
\qquad(\mathrm{n}=8)\end{array}$ & $\begin{array}{l}\text { EPI-Low } \\
\qquad(n=9)\end{array}$ & $\begin{array}{l}\text { EPI-Middle } \\
(\mathrm{n}-8)\end{array}$ & $\begin{array}{l}\text { EPI-High } \\
\quad(n=8)\end{array}$ \\
\hline BW (g) & $389.7 \pm 16.9$ & $311.1 \pm 35.4$ & $273.4 \pm 11.3$ & $262.8 \pm 7.8$ & $314.7 \pm 9.2$ & $274.4 \pm 8.0$ \\
\hline LVW (g) & $0.82 \pm 0.04$ & $0.84 \pm 0.05$ & $0.67 \pm 0.03^{\mathrm{c}}$ & $0.67 \pm 0.04^{\mathrm{c}}$ & $0.75 \pm 0.04$ & $0.63 \pm 0.03^{\mathrm{c}}$ \\
\hline LVWI & $2.11 \pm 0.08^{\mathrm{a}}$ & $2.86 \pm 0.21$ & $2.49 \pm 0.14^{\mathrm{b}}$ & $2.53 \pm 0.12$ & $2.38 \pm 0.11^{\mathrm{b}}$ & $2.31 \pm 0.08^{\mathrm{c}}$ \\
\hline HR (bpm) & $400.5 \pm 13.3^{\mathrm{a}}$ & $453.3 \pm 10.8$ & $347.5 \pm 9.9^{c}$ & $454.5 \pm 10.4$ & $428.0 \pm 17.0$ & $366.7 \pm 3.7^{\mathrm{c}}$ \\
\hline LVSP (mmHg) & $120.2 \pm 2.3^{\mathrm{a}}$ & $104.8 \pm 1.7$ & $100.1 \pm 1.5$ & $106.8 \pm 2.3$ & $109.4 \pm 3.5$ & $112.7 \pm 2.1^{\mathrm{c}}$ \\
\hline LVEDP (mmHg) & $1.2 \pm 0.6^{\mathrm{a}}$ & $11.1 \pm 0.6$ & $5.4 \pm 0.3^{\mathrm{c}}$ & $8.6 \pm 0.2^{c}$ & $7.6 \pm 0.28^{c}$ & $6.1 \pm 0.4^{\mathrm{c}}$ \\
\hline $\mathrm{dp} / \mathrm{dt}_{\max }(\mathrm{mmHg} / \mathrm{sec})$ & $3.82 \pm 0.05^{\mathrm{a}}$ & $2.33 \pm 0.05$ & $3.37 \pm 0.04^{\mathrm{c}}$ & $2.56 \pm 0.04^{\mathrm{c}}$ & $2.91 \pm 0.07^{\mathrm{c}}$ & $3.29 \pm 0.04^{\mathrm{c}}$ \\
\hline $\mathrm{dp} / \mathrm{dt}_{\min }(\mathrm{mmHg} / \mathrm{sec})$ & $-3.61 \pm 0.02^{\mathrm{a}}$ & $-1.90 \pm 0.07$ & $-2.84 \pm 0.04^{c}$ & $-2.20 \pm 004^{c}$ & $-2.55 \pm 0.04^{c}$ & $-2.67 \pm 0.04^{c}$ \\
\hline
\end{tabular}

BW, body weight; LVW, left ventricular weight; LVWI, left ventricular weight index; HR, heart rate; bpm, beats per minute; LVSP, left ventricular systolic pressure; LVEDP, left ventricular end diastolic pressure; $\mathrm{dp} / \mathrm{dt}_{\max }$, maximal rate of LV pressure rise; $\mathrm{dp} / \mathrm{dt}_{\min }, \mathrm{maximal}$ rate of LV pressure decline. Normal, normal rats without isoproterenol injection; control, model rats treated with normal saline after isoproterenol injection; metoprolol, model rats treated with $8 \mathrm{mg} / \mathrm{kg}$ of metoprolol after isoproterenol injection; EPI-Low, EPI-Middle and EPI-High: model rats treated with 50,100 and $200 \mathrm{mg} / \mathrm{kg}$ of EPI-ext after isoproterenol injection, respectively. Values are the mean \pm SEM. ${ }^{\mathrm{a}} \mathrm{P}<0.01$ vs control (Student's t-test); ${ }^{\mathrm{b}} \mathrm{P}<0.05,{ }^{\mathrm{c}} \mathrm{P}<0.01$ vs control (Dunnett's test).

Table II. Plasma cytokine parameters in rats 12 weeks after isoproterenol injection treated either with normal saline, metoprolol or various doses of EPI-ext.

\begin{tabular}{|c|c|c|c|c|c|c|}
\hline \multirow[t]{2}{*}{ Parameter } & \multirow[t]{2}{*}{ Normal $(n=8)$} & \multicolumn{5}{|c|}{ Isoproterenol injection } \\
\hline & & $\begin{array}{l}\text { Control } \\
(n=10)\end{array}$ & $\begin{array}{l}\text { Metoprolol } \\
\quad(n=8)\end{array}$ & $\begin{array}{l}\text { EPI-Low } \\
\qquad(n=9)\end{array}$ & $\begin{array}{l}\text { EPI-Middle } \\
(\mathrm{n}-8)\end{array}$ & $\begin{array}{l}\text { EPI-High } \\
\qquad(\mathrm{n}=8)\end{array}$ \\
\hline TNF- $\alpha(\mathrm{pg} / \mathrm{ml})$ & $372 \pm 22^{\mathrm{a}}$ & $1026 \pm 75$ & $905 \pm 64$ & $572 \pm 20^{c}$ & $501 \pm 40^{c}$ & $411 \pm 29^{c}$ \\
\hline $\mathrm{NE}(\mathrm{ng} / \mathrm{ml})$ & $33.0 \pm 4.6^{\mathrm{a}}$ & $80.9 \pm 6.3$ & $68.2 \pm 14.7$ & $81.1 \pm 16.2$ & $69.0 \pm 13.0$ & $62.1 \pm 4.84^{\mathrm{b}}$ \\
\hline Ang II (pg/ml) & $270.6 \pm 53.5^{\mathrm{a}}$ & $661.7 \pm 34.2$ & $515.7 \pm 44.0^{\mathrm{b}}$ & $587.5 \pm 44.8$ & $526.8 \pm 44.9^{b}$ & $502.1 \pm 61.4^{\mathrm{b}}$ \\
\hline $\mathrm{BNP}(\mathrm{pg} / \mathrm{ml})$ & $48.89 \pm 6.1^{\mathrm{a}}$ & $216.8 \pm 15.8$ & $162.6 \pm 17.0^{\mathrm{b}}$ & $215.6 \pm 12.7$ & $165.5 \pm 13.3^{b}$ & $143.3 \pm 19.2^{b}$ \\
\hline
\end{tabular}

TNF- $\alpha$, tumor necrosis factor $\alpha$; NE, norepinephrine; Ang II, angiotensin II; BNP, brain natriuretic peptide. Normal, normal rats without isoproterenol injection; control, model rats treated with normal saline after isoproterenol injection; metoprolol, model rats treated with $8 \mathrm{mg} / \mathrm{kg}$ of metoprolol after isoproterenol injection; EPI-Low, EPI-Middle and EPI-High: model rats treated with 50, $100 \mathrm{and} 200 \mathrm{mg} / \mathrm{kg}$ of EPI-ext after isoproterenol injection, respectively. Values are the mean $\pm \mathrm{SEM} .{ }^{\mathrm{a}} \mathrm{P}<0.01$ vs control (Student's t-test); ${ }^{b} \mathrm{P}<0.05,{ }^{\mathrm{c}} \mathrm{P}<0.01 \mathrm{vs}$ control (Dunnett's test).

followed by Dunnett's test when the data involved three or more groups. $\mathrm{P}<0.05$ was considered to be significant.

\section{Results}

EPI-ext ameliorated isoproterenol-induced CHF in rats Cardiac morphometric parameters and hemodynamic parameters. As shown in Table I, isoproterenol administration resulted in severe heart failure, as shown by the increased levels of LV weight index (LVWI) and heart rate (HR), as well as LV end diastolic pressure (LVEDP), and by the decreased levels of LV systolic pressure (LVSP), maximal rate of LV pressure rise $\left(\mathrm{dp} / \mathrm{dt}_{\max }\right)$, and maximal rate of $\mathrm{LV}$ pressure decline $\left(\mathrm{dp} / \mathrm{dt}_{\min }\right)$. Against these, EPI-ext dose-dependently reversed the changes of these cardiac morphometric and hemodynamic parameters. The positive control metoprolol also ameliorated LV dysfunction.

Plasma cytokines. EPI-ext significantly reduced the plasma levels of TNF- $\alpha$, NE, Ang II, and BNP in a dosedependent manner in rats with $\mathrm{CHF}$ caused by isoproterenol (Table II).

Histopathological changes. EPI-ext remarkably improved the histological changes including cadiocyte hypertrophy, cadiocyte degeneration, inflammatory infiltration, and cardiac desmoplasia (Fig. 1). The improvement in metoprolol-treated rats was also significant (Fig. 1). 


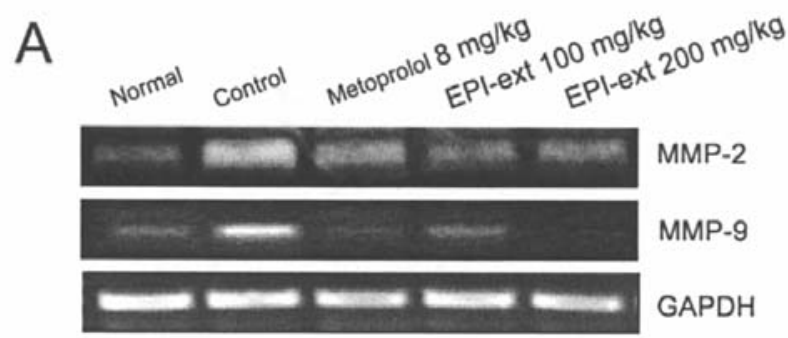

$\mathrm{B}$

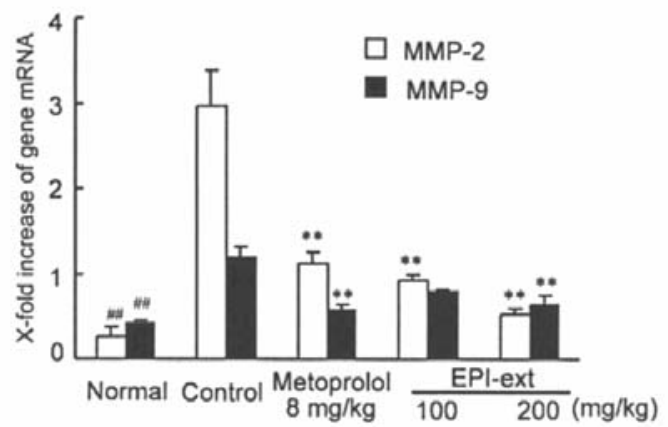

C

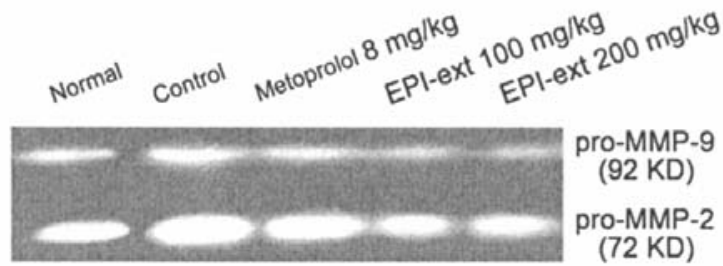

Figure 2. Effect of EPI-ext on the message RNA expression and activities of MMP-2 and -9 of the LV in rats with CHF caused by isoproterenol. (A) MMP-2 and -9 mRNA expression of the LV in rats with CHF was examined by RT-PCR. The graph shown here is one of three different experiments. (B) MMP-2 and -9 mRNA expression was examined by real-time PCR. Each column represents the mean \pm SEM of three independent experiments and each experiment includes triplicate sets. ${ }^{\# \#} \mathrm{P}<0.01$ vs control (Student's ttest); ${ }^{*} \mathrm{P}<0.05,{ }^{* *} \mathrm{P}<0.01$ vs control (Dunnett's test). (C) MMP-2 and -9 activities were examined by gelatin zymography assay. The graph shown here is one of three different experiments.
EPI-ext reduced MMP-2 and -9 expression and activities of $L V$ in rats with CHF caused by isoproterenol. As shown in Fig. 2A, MMP-2 and -9 mRNA expression of LV was pronouncedly increased in model rats with $\mathrm{CHF}$ caused by isoproterenol. Against this, EPI-ext significantly downregulated MMP-2 and -9 mRNA expression in a dosedependent manner. This result was further confirmed by real-time PCR (Fig. 2B). Moreover, the activities of MMP-2 and -9 were also suppressed by EPI-ext using gelatin zymography assay (Fig. 2C).

EPI-ext inhibited myocardial apoptosis of the $L V$ in rats with CHF caused by isoproterenol. The oligonucleosomal fragmentation of myocardial DNA from rats with CHF was shown in a DNA ladder pattern in agarose gel electrophoresis (Fig. 3A, control). Treatment with EPI-ext significantly prevented DNA laddering. The protein expression of Bax, cleaved caspase- 9 and cleaved caspase- 3 in the control group increased compared with that in the normal group, whilst Bcl-2 expression decreased significantly. Against these, EPIext reversed these changes (Fig. 3B).

The content of icariin in EPI-ext. As shown in Fig. 4, the main component in EPI-ext was determined by HPLC as $16.7 \%(\mathrm{w} / \mathrm{w})$ icariin.

\section{Discussion}

Cardiac remodeling is a dynamic response of the heart to injury and a critical component in the development of $\mathrm{CHF}$. There is increasing evidence that inhibition of cardiac remodeling may be a novel drug target for the treatment of CHF (4). Epimedium is a traditional Chinese medicine currently being evaluated for the treatment of cardiovascular diseases. However, little is known of the mechanism by which it exerts a protective role in heart failure. In the present study, we first investigated the therapeutic efficacy of
A

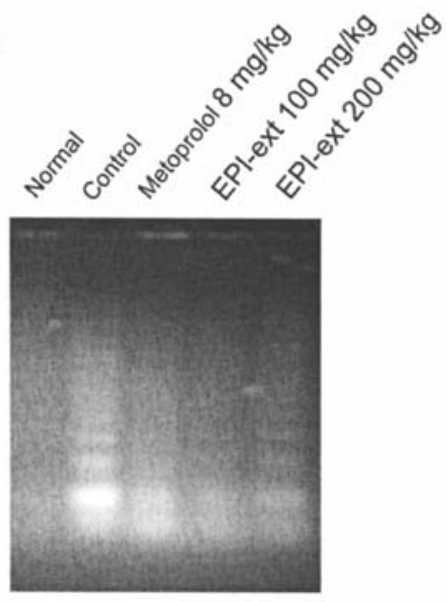

B

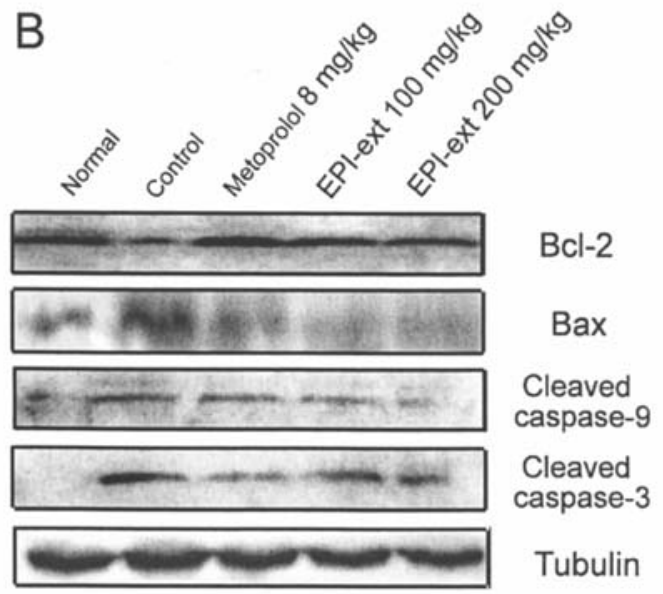

Figure 3. Effect of EPI-ext on myocardial apoptosis of the LV in rats with CHF caused by isoproterenol. (A) A representative result of cadiocyte DNA fragmentation electrophoresis. (B) Bcl-2, Bax, cleaved caspase- 9 and cleaved caspase-3 expression in the LV were examined by Western blot analysis. The graph shown here is one of three different experiments. 

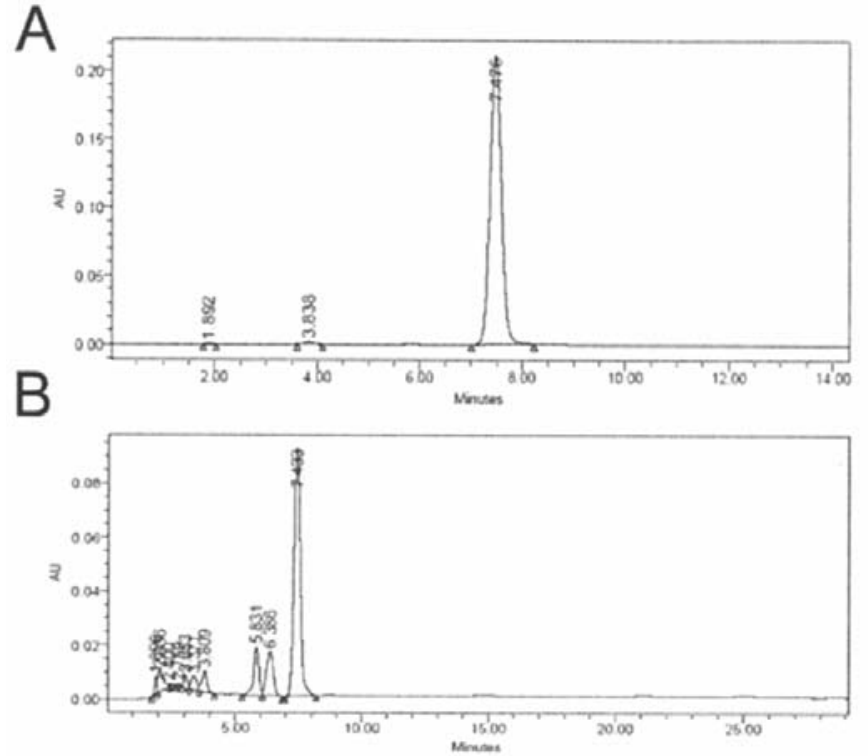

Figure 4. HPLC analysis of the content of icariin in EPI-ext. EPI-ext was applied to a $\mathrm{C} 18$ column and eluted with $\mathrm{CH}_{3} \mathrm{OH} / \mathrm{H}_{2} \mathrm{O}(45 / 55$, v/v). The effluents were detected under $270 \mathrm{~nm}$. Column temperature was set at $25^{\circ} \mathrm{C}$ and the flow rate was $1 \mathrm{ml} / \mathrm{min}$. For peak assignment, the standard compound icariin (A) was applied to HPLC and eluted under the same chromatographic conditions as those used in EPI-ext (B). The peaks representing constituents of EPI-ext were identified by comparing their retention time with the standard compounds.

ethanol extract of epimedium (EPI-ext) in rats with CHF induced by isoproterenol. We observed that EPI-ext significantly improved LV function, inhibited inflammatory cytokine production and MMP activity, and reduced myocardial apoptosis. The effect of EPI-ext on LV morphology, remodeling and function was comparable to the effect observed with the positive control $\beta$-blocking agent metoprolol, which has a beneficial effect in the treatment of heart failure $(9,25)$.

$\mathrm{CHF}$ in the rats induced by isoproterenol is accompanied by myocardial dysfunction (21). In the present study, EPI-ext significantly improved the following hemodynamic parameters: LVSP, LVEDP, HR, dp/dt $\mathrm{max}_{\max }$ and $\mathrm{dp} / \mathrm{dt}_{\min }$ in rats with CHF (Table I). Importantly, histological examination of LV sections from the control rats without medication showed marked cadiocyte hypertrophy, cadiocyte degeneration, inflammatory infiltration, and cardiac desmoplasia (Fig. 1). Treatment with EPI-ext dose-dependently reduced the extent of heart damage and especially inhibited collagen hyperplasia and LV fibrosis. Cardiac remodeling in rats with CHF is characterized by interstitial and perivascular deposition of fibrillar collagen leading to cardiac muscle stiffness and LV dysfunction and hence, to progressive cardiac dysfunction and heart failure (26). Fibrosis in the myocardium is a major determinant of cardiac remodeling in ischemic cardiomyopathy (27). In the present study, EPI-ext also dosedependently decreased the content of hydroxyproline in LV (data not shown). In line with the results from Masson staining (Fig. 1), we confirmed that EPI-ext impaired LV fibrosis in rats with CHF. Thus, we demonstrated that EPI-ext significantly improved LV systolic and diastolic function and attenuated LV fibrosis in rats with $\mathrm{CHF}$ induced by isoproterenol.

Isoproterenol-induced heart failure is thought to be a suitable model of CHF. LV dysfunction and cardiac remodeling play a crucial role in the process of $\mathrm{CHF}$. Noteworthy, heart failure induced by isoproterenol results in the elevation of various plasma cytokines including TNF- $\alpha$, NE, Ang II and BNP, which are responsible for the development of CHF (28-31). TNF- $\alpha$ is a cytokine that may play a role in the pathogenesis of heart failure. In patients with heart failure, increased levels of TNF- $\alpha$ were observed that were high enough to reduce cardiac contractility in vitro. The mortality of heart failure patients increases with higher levels of TNF- $\alpha$. For these reasons, inhibition of TNF- $\alpha$ appears to be a valid target for the improvement of heart failure therapy (28). Inhibition of NE in plasma has been proved beneficial for patients with chronic heart failure (29). Ang II, frequently elevated in CHF patients, contributes to decreased arterial distensibility (30). BNP, a peptide hormone secreted chiefly by ventricular myocytes, plays a key role in volume homeostasis. The plasma concentration of BNP is raised in various pathological states, especially heart failure. Many studies suggest that the measurement of plasma BNP has clinical utility for excluding a diagnosis of heart failure in patients with dyspnea or fluid retention and for providing prognostic information in those with heart failure or other cardiac disease (31). In line with the results from hemodynamic and histological examination, EPI-ext significantly reduced the plasma levels of TNF- $\alpha, \mathrm{NE}, \mathrm{Ang}$ II, and BNP in a dose-dependent manner in rats with $\mathrm{CHF}$. These findings suggest that EPI-ext attenuates LV dysfunction and cardiac remodeling.

MMPs are an endogenous family of proteolytic enzymes implicated in cardiac remodeling. Gene expression and gelatinolytic activity of MMPs in the LV were significantly increased in experimental myocardial infarction in mice (32), in hypertensive rats $(33,34)$, in rats with progressive heart failure (7), and, most importantly, in patients with heart failure $(5,35)$. Previous studies demonstrated that pharmacological inhibition of MMPs resulted in suppression of cardiac remodeling in animal models of $\mathrm{CHF}(7,36,37)$. In addition, there is evidence that the beneficial effects of angiotensinconverting enzyme inhibitors on cardiac remodeling is due to the inhibition of collagen synthesis as well as the influence on MMPs, particularly MMP-2 (38). Taking these findings into account, there is no doubt that MMPs play a crucial role in promoting cardiac remodeling. Considering the expression and activities of MMP-2 and -9 were also blocked by EPI-ext (Fig. 2), it is conceivable to assume that in our study EPI-ext exerted an inhibitory effect on MMP-2 and -9 , leading to the prevention of cardiac remodeling and dysfunction.

Myocardial apoptosis has been causally linked to the pathogenesis of heart failure $(39,40)$. Some apoptotic proteins including $\mathrm{Bcl}-2$, Bax and caspase- 3 are involved in the development of myocardial apoptosis (40). Bcl-2 family proteins may be either pro- or anti-apoptotic including Bcl-2, Bcl-xl, Bax, and Bid. Bcl-2 itself inhibits apoptosis in response to a wide variety of signals and overexpression of Bcl-2 can protect cardiac myocytes (41). Bax, on the contrary, is a pro-apoptotic protein of the Bcl-2 family and a 
decreased $\mathrm{Bcl}-2 / \mathrm{Bax}$ ratio has been shown to increase the probability for myocardial cell apoptosis (42). Caspases, a subclass of cysteine proteases that cleave substrates after aspartic acid residues, are central to the execution of apoptosis (43). Cardiac myocytes undergo apoptosis in response to a myriad of stimuli including $\beta$-adrenergic agonists (44), Ang II (45), TNF- $\alpha$ (46) and so on. Several studies in rats and humans with heart failure have demonstrated that inhibition of myocardial apoptosis provided beneficial effects on cardiac remodeling and $\mathrm{LV}$ function $(47,48)$. In our study, myocardial apoptosis was obviously induced by isoproterenol injection. EPI-ext remarkably inhibited cadiocyte DNA fragmentation and attenuated myocardial apoptosis by down-regulating Bax, caspase-9, caspase-3 expression and up-regulating Bcl-2 expression of cadiocytes (Fig. 3). We speculate that EPI-ext reduced cardiac remodeling at least in part by inhibiting myocardial apoptosis. Considering icariin is one of the major components of epimedium, we demonstrated that there was $16.7 \%(w / w)$ of icariin in EPI-ext. However, whether the anti-heart failure effect of EPI-ext is due to icariin needs further investigation.

In conclusion, EPI-ext significantly improved LV remodeling and function in rats with $\mathrm{CHF}$ induced by isoproterenol. The beneficial effect of EPI-ext in animal models of CHF may be mediated at least in part by the inhibition of elevated MMP-2 and 9 activities as well as myocardial apoptosis and this effect contributes to the amelioration of $\mathrm{CHF}$ diseases in clinical conditions.

\section{Acknowledgements}

This study was supported by Nanjing Bureau of Science and Technology, Nanjing, P.R. China (no. 2005ZD0523).

\section{References}

1. van Zwieten PA: Drug treatment of congestive heart failure. Semin Cardiothorac Vasc Anesth 7: 13-17, 2003.

2. Jugdutt BI: Ventricular remodeling after infarction and the extracellular collagen matrix: when is enough enough? Circulation 108: 1395-1403, 2003.

3. Brower GL, Gardner JD, Forman MF, Murray DB, Voloshenyuk T, Levick SP and Janicki JS: The relationship between myocardial extracellular matrix remodeling and ventricular function. Eur J Cardiothorac Surg 30: 604-610, 2006.

4. Dhalla NS, Dent MR, Tappia PS, Sethi R, Barta J and Goyal RK: Subcellular remodeling as a viable target for the treatment of congestive heart failure. J Cardiovasc Pharmacol Ther 11: 31-45, 2006.

5. Spinale FG, Coker ML, Heung LJ, Bond BR, Gunasinghe HR, Etoh T, Goldberg AT, Zellner JL and Crumbley AJ: A matrix metalloproteinase induction/activation system exists in the human left ventricular myocardium and is upregulated in heart failure. Circulation 102: 1944-1949, 2000.

6. Creemers EEJM, Cleutjens JPM, Smits JFM and Daemen MJAP: Matrix metalloproteinase inhibition after myocardial infarction: a new approach to prevent heart failure? Circ Res 89: 201-210, 2001.

7. Peterson JT, Hallak H, Johnson L, Li H, O'Brien PM, Sliskovic DR, Bocan TMA, Coker ML, Etoh T and Spinale FG: Matrix metalloproteinase inhibition attenuates left ventricular remodeling and dysfunction in a rat model of progressive heart failure. Circulation 103: 2303-2309, 2001.

8. Dixon IM, Ju H, Jassal DS and Peterson DJ: Effect of ramipril and losartan on collagen expression in right and left heart after myocardial infarction. Mol Cell Biochem 165: 31-45, 1996.
9. Bristow MR: Mechanism of action of beta-blocking agents in heart failure. Am J Cardiol 80: 26-40, 1997.

10. Gao SQ, Fu DX and Zhang HM: Progress in the prevention and cure of osteoporosis by Epimedium and its prescription. China J Chin Materia Medica 24: 249-251, 1999 (In Chinese).

11. Han B and Yang JS: Pharmacological research of Epimedium. Chin Trad Herbal Drugs 31: 873-875, 2000 (In Chinese).

12. Ye LK and Chen JM: Advances in study on pharmacological effects of epimedium. China J Chin Materia Medica 26: 293-295, 2001 (In Chinese).

13. Huang XL, Wang W and Zhou YW: Protective effect of epimedium flavonoids injection on experimental myocardial infarction rats. Zhongguo Zhong Xi Yi Jie He Za Zhi 26: 68-71, 2006.

14. Kovacevic N, Colic M, Backovic A and Doslov-Kokorus Z: Immunomodulatory effects of the methanolic extract of Epimedium alpinum in vitro. Fitoterapia 77: 561-567, 2006.

15. Lee MK, Choi YJ, Sung SH, Shin DI, Kim JW and Kim YC: Antihepatotoxic activity of icariin, a major constituent of Epimedium koreanum. Planta Med 61: 523-526, 1995.

16. Liang HR, Vuorela P, Vuorela $\mathrm{H}$ and Hiltunen R: Isolation and immunomodulatory effect of flavonol glycosides from Epimedium hunanense. Planta Med 63: 316-319, 1997.

17. Wu H, Lien EJ and Lien LL: Chemical and pharmacological investigations of Epimedium species: a survey. Prog Drug Res 60: 1-57, 2003.

18. Li YB, Meng FH, Lu XM and Li FM: Chemical constituents from herb of Epimedium brevicornum. Zhongguo Zhong Yao Za Zhi 30: 586-588, 2005.

19. Pan Y, Kong LD, Li YC, Xia X, Kung HF and Jiang FX: Icariin from Epimedium brevicornum attenuates chronic mild stressinduced behavioral and neuroendocrinological alterations in male Wistar rats. Pharmacol Biochem Behav 87: 130-140, 2007.

20. Yap SP, Shen P, Butler MS, Gong Y, Loy CJ and Yong EL: New estrogenic prenylflavone from Epimedium brevicornum inhibits the growth of breast cancer cells. Planta Med 71: 114-119, 2005.

21. Teerlink JR, Pfeffer JM and Pfeffer MA: Progressive ventricular remodeling in response to diffuse isoproterenol-induced myocardial necrosis in rats. Circ Res 75: 105-113, 1994.

22. Davani S, Marandin A, Mersin N, Royer B, Kantelip B, Hervé P, Etievent JP and Kantelip JP: Mesenchymal progenitor cells differentiate into an endothelial phenotype, enhance vascular density, and improve heart function in a rat cellular cardiomyoplasty model. Circulation 108: 253-258, 2003.

23. Torimura T, Ueno T, Kin M, Harada R, Nakamura T, Sakamoto M, Kumashiro R, Yano H, Kojiro $M$ and Sata M: Laminin deposition to type IV collagen enhances haptotaxis, chemokinesis, and adhesion of hepatoma cells through 31 integrins. J Hepatol 35: 245-253, 2001.

24. Zhang XM, Chen J, Xia YG and Xu Q: Apoptosis of murine melanoma B 16-BL6 cells induced by quercetin targeting mitochondria, inhibiting expression of PKC- $\alpha$ and translocating PKC- $\delta$. Cancer Chemother Pharmacol 55: 251-262, 2005.

25. Bristow MR: $ß$-adrenergic receptor blockade in chronic heart failure. Circulation 101: 558-569, 2000.

26. Caulfield JB and Borg TK: The collagen network of the heart. Lab Invest 40: 364-372, 1979.

27. Beltrami CA, Finato N, Rocco M, Feruglio GA, Puricelli C, Cigola E, Quaini F, Sonnenblick EH, Olivetti G and Anversa P: Structural basis of end-stage failure in ischemic cardiomyopathy in humans. Circulation 89: 151-163, 1994.

28. Muller-Ehmsen J and Schwinger RH: TNF and congestive heart failure: therapeutic possibilities. Expert Opin Ther Targets 8: 203-209, 2004.

29. Swedberg K, Bristow MR, Cohn JN, Dargie H, Straub M, Wiltse $\mathrm{C}$ and Wright TJ: Effects of sustained-release moxonidine, an imidazoline agonist, on plasma norepinephrine in patients with chronic heart failure. Circulation 105: 1797-1803, 2002.

30. Lage SG, Kopel L, Medeiros CCJ, Carvalho RT and Creager MA: Angiotensin II contributes to arterial compliance in congestive heart failure. Am J Physiol Heart Circ Physiol 283: H1424H1429, 2002.

31. Cowie MR and Mendez GF: BNP and congestive heart failure. Prog Cardiovasc Dis 44: 293-321, 2002.

32. Rohde LE, Ducharme A, Arroyo LH, Aikawa M, Sukhova GH, Lopez-Anaya A, McClure KF, Mitchell PG, Libby P and Lee RT: Matrix metalloproteinase inhibition attenuates early left ventricular enlargement after experimental myocardial infarction in mice. Circulation 99: 3063-3070, 1999. 
33. Iwanaga Y, Aoyama T, Kihara Y, Onozawa Y, Yoneda T and Sasayama S: Excessive activation of matrix metalloproteinases coincides with left ventricular remodeling during transition from hypertrophy to heart failure in hypertensive rats. J Am Coll Cardiol 39: 1384-1391, 2002.

34. Sakata Y, Yamamoto K, Mano T, Nishikawa N, Yoshida J, Hori M, Miwa T and Masuyama T: Activation of matrix metalloproteinases precedes left ventricular remodeling in hypertensive heart failure rats: its inhibition as a primary effect of angiotensin-converting enzyme inhibitor. Circulation 109: 2143-2149, 2004.

35. Thomas CV, Coker ML, Zellner JL, Handy JR, Crumbley AJ and Spinale FG: Increased matrix metalloproteinase activity and selective upregulation in LV myocardium from patients with end-stage dilated cardiomyopathy. Circulation 97: 1708-1715, 1998.

36. Spinale FG, Coker ML, Krombach SR, Mukherjee R, Hallak H, Houck WV, Clair MJ, Kribbs SB, Johnson LL, Peterson JT and Zile MR: Matrix metalloproteinase inhibition during the development of congestive heart failure: effects on left ventricular dimensions and function. Circ Res 85: 364-376, 1999.

37. Chancey AL, Brower GL, Peterson JT and Janicki JS: Effects of matrix metalloproteinase inhibition on ventricular remodeling due to volume overload. Circulation 105: 1983-1988, 2002.

38. Seeland U, Kouchi I, Zolk O, Itter G, Linz W and Bohm M: Effect of ramipril and furosemide treatment on interstitial remodeling in post-infarction heart failure rat hearts. J Mol Cell Cardiol 34: 151-163, 2002

39. Wencker D, Chandra M, Nguyen K, Miao W, Garantziotis S, Factor SM, Shirani J, Armstrong RC and Kitsis RN: A mechanistic role for cardiac myocyte apoptosis in heart failure. J Clin Invest 111: 1497-1504, 2003.

40. Crow MT, Mani K, Nam YJ and Kitsis RN: The mitochondrial death pathway and cardiac myocyte apoptosis. Circ Res 95: 957-970, 2004.
41. Gustafsson $A B$ and Gottlieb RA: Bcl-2 family members and apoptosis, taken to heart. Am J Physiol Cell Physiol 292: 45-51, 2007.

42. Condorelli G, Morisco C, Stassi G, Notte A, Farina F, Sgaramella G, de Rienzo A, Roncarati R, Trimarco B and Lembo G: Increased cardiomyocyte apoptosis and changes in proapoptotic and antiapoptotic genes bax and bcl-2 during left ventricular adaptations to chronic pressure overload in the rat. Circulation 99: 3071-3078, 1999.

43. Thornberry NA and Lazebnik Y: Caspases: enemies within. Science 281: 1312-1316, 1998

44. Shizukuda Y, Buttrick PM, Geenen DL, Borczuk AC, Kitsis RN and Sonnenblick EH: $B$-adrenergic stimulation causes cardiocyte apoptosis: influence of tachycardia and hypertrophy. Am J Physiol 275: 961-968, 1998.

45. Kajstura J, Cigola E, Malhotra A, Li P, Cheng W, Meggs LG and Anversa P: Angiotensin II induces apoptosis of adult ventricular myocytes in vitro. J Mol Cell Cardiol 29: 859-870, 1997.

46. Krown KA, Page MT, Nguyen C, Zechner D, Gutierrez V, Comstock, KL, Glembotski CC, Quintana PJ and Sabbadini RA: Tumor necrosis factor alpha-induced apoptosis in cardiac myocytes: involvement of the sphingolipid signaling cascade in cardiac cell death. J Clin Invest 98: 2854-2865, 1996.

47. Abbate A, Bussani R, Biondi-Zoccai GGL, Rossiello R, Silvestri F, Baldi F, Biasucci LM and Baldi A: Persistent infarct-related artery occlusion is associated with an increased myocardial apoptosis at postmortem examination in humans late after an acute myocardial infarction. Circulation 106: 1051-1054, 2002.

48. Chandrashekhar Y, Sen S, Anway R and Shuros A: Long-term caspase inhibition ameliorates apoptosis, reduces myocardial troponin-I cleavage, protects left ventricular function, and attenuates remodeling in rats with myocardial infarction. J Am Coll Cardiol 43: 295-301, 2004. 